\title{
Thoracoscopic thymomectomy with the da Vinci computer-enhanced surgical system
}

\author{
Ichiro Yoshino, MD, a Makoto Hashizume, MD, FACS, ${ }^{\text {b } M i t s u o ~ S h i m a d a, ~ M D, ~ a ~ M o r i m a s a ~ T o m i k a w a, ~ M D, ~ a ~}$ \\ Makiko Tomiyasu, MD, ${ }^{a}$ Ryuichi Suemitsu, MD, and Keizo Sugimachi, MD, FACS, ${ }^{\text {b }}$ Fukuoka, Japan
}

From the Department of Surgery and Science $^{\mathrm{a}}$ and the Department of Disaster and Emergency Medicine, ${ }^{\mathrm{b}}$ Graduate School of Medical Sciences, Kyushu University, Fukuoka, Japan.

Received for publication Jan 19, 2001; accepted for publication Feb 19, 2001.

Address for reprints: Ichiro Yoshino, MD, $\mathrm{PhD}$, Department of Surgery and Science, Graduate School of Medical Sciences, Kyushu University, 3-1-1 Maidashi, Fukuoka 812-8582, Japan (E-mail: iyoshino@surg2.med.kyushu-u.ac.jp).

J Thorac Cardiovasc Surg 2001;122:783-5

Copyright (C) 2001 by The American Association for Thoracic Surgery

0022-5223/2001 $\$ 35.00+0 \quad \mathbf{1 2 / 5 4 / 1 1 5 2 3 1}$

doi: $10.1067 / \mathrm{mtc} .2001 .115231$

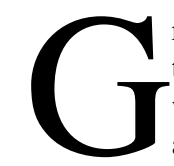
reat progress has recently been made in the development of robotic surgical systems. Master-slave manipulators, which are now available for use in operations, were first introduced in the field of coronary arterial bypass grafting 2 years ago. ${ }^{1,2}$ For general operations, more than a thousand patients worldwide have now undergone robot-assisted operations with this system, including cholecystectomy, Nissen fundoplication, tubular restoration, esophagogastroplasty, and repair of groin hernia. ${ }^{3}$ Recently, thoracoscopic operations have been widely indicated for such intrathoracic diseases as pneumothorax, lung cancer, and mediastinal tumors, as well as biopsy of various lung diseases. As a result, general thoracic surgery is now expected to be the next field in which to test this robotic system. The main reason for the lack of such a surgical attempt thus far has been the absence of a proper position for the thoracic ports for the robotic arms. We herein report the findings of the first ever successful thoracoscopic operation with a robotic surgical system, the da Vinci Surgical System (Intuitive Surgical, Inc, Mountain View, Calif), ${ }^{1,3}$ for the extirpation of an anterior mediastinal tumor.

\section{Clinical Summary}

A 74-year-old man had been receiving medication for hypertension for 10 years and was managed by his family doctor. He felt right anterior chest pain in August 2000. No abnormal finding was observed on chest radiography or electrocardiography other than an old tuberculosis scar on the right lung, but computed tomography of the chest revealed a well-demarcated solid mass measuring $2.5 \mathrm{~cm}$ in diameter in the anterior mediastinum. The lesion had increased in size to $3.0 \mathrm{~cm}$ in diameter at follow-up computed tomography in December 2000 (Figure 1). The patient was therefore admitted to the Second Department of Surgery, Kyushu University Hospital, Fukuoka, Japan, and scheduled to undergo surgical treatment.

Imaging strongly suggested noninvasive thymoma, and therefore a video-assisted thoracoscopic extirpation was considered. Our department had already performed 19 laparoscopic operations with the aid of the da Vinci robotic surgical system, including such operations as distal partial gastrectomy, colectomy, splenectomy, and extirpation of a benign tumor of the intraabdominal esophagus during the 4-month period from August to November 2000. ${ }^{3}$ We therefore planned to perform a thoracoscopic operation with this robotic system. On December 18, 2000, the operation was performed.

After achievement of adequate general and epidural anesthesia, the patient was placed in the hemi-left lateral position. First, a minithoracotomy measuring $4 \mathrm{~cm}$ in length was made at the seventh intercostal space of the midaxillary region, and the thoracic cavity was explored by means of conventional video-assisted thoracoscopy. There was neither severe pleural adhesion nor pleural dissemination, and the mass was observed in the anterior mediastinal fat tissue. Next, the patient-side manipulator was placed at the left cranial site, and conventional thoracoscopy was changed to use of the 3-dimensional stereoendoscope of the da Vinci system. Two thoracic ports were inserted through the fifth intercostal space on the midaxillary line and the sixth intercostal space on the midclavicular line, and then 2 arms of the da Vinci system were attached to these two access points while another one was attached 


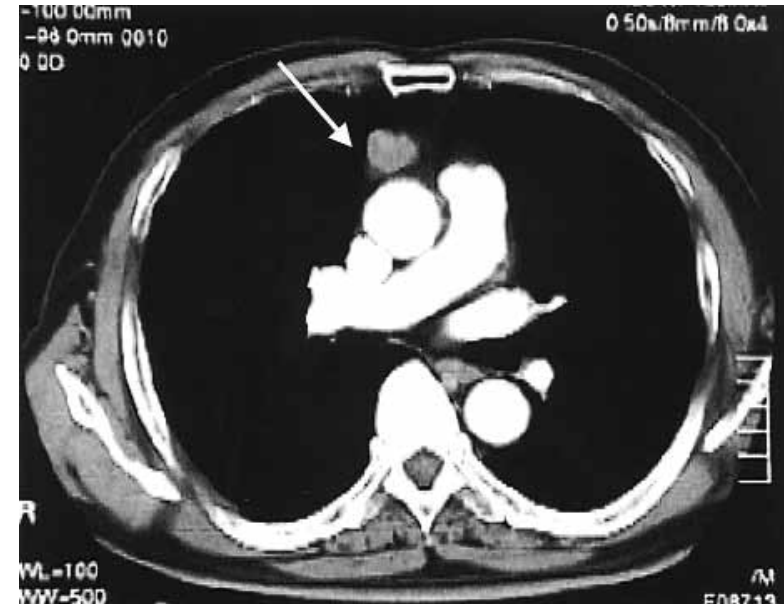

Figure 1. Computed tomographic imaging of the mediastinal mass. An encapsulated solid mass measuring $3.5 \mathrm{~cm}$ in diameter is recognized in the anterior mediastinum.

to the port-inserted endoscope. For the left arm, which was mainly used to grasp the adjacent tissue of the tumor, an EndoWrist instrument (Intuitive Surgical) was used, and for the right arm, which was used to perform the dissection, an EndoDissector device (Intuitive Surgical) with electric cautery function was mainly used (Figure 2, A). Conventional instruments for endoscopic operations, such as scissors or grasper forceps, were introduced from the window of the seventh intercostal wound to be used in conjunction with the da Vinci instruments. After a mediastinotomy, the tumor was extirpated from the anterior mediastinal fat tissue and thymic tissue in a blunt and sharp manner. A drainage vein was ligated with a 3-0 Vicryl polyglactin (Ethicon, Inc, Somerville, NJ) and then was cut (Figure 2,B). The tumor was completely resected with an adequate margin, placed in an endo-pouch, and then passed from the thoracic cavity through the wound at the seventh intercostal space. Minor oozing at the resection margin was controlled by an over-and-over suture with 3-0 Vicryl. After irrigation with warm saline solution and the insertion of a $28 \mathrm{~F}$ drainage tube through the wound of the sixth intercostal space, the other wounds were closed. These intrathoracic procedures were completely performed by the manipulators. The total operative time was 2 hours 10 minutes, and the estimated blood loss was $30 \mathrm{~g}$. The patient was taken to a recovery room of the surgical ward. The postoperative course was uneventful, and the thoracic drain was extubated on the first day. The resected specimen revealed a well-capsulated and well-lobulated mass and was histologically diagnosed as a thymoma of Masaoka stage I.

\section{Discussion}

This is the first report of a robotic operation for a mediastinal tumor and may provide important information for thoracic surgeons. First, the selection of the posture and access routes used in this case were found to be feasible for the anterior mediastinum. The position of these 3 holes was highly restricted because the distance between the 2 arms holding the instruments requires a minimum space of $15 \mathrm{~cm}$. In addition, this operative experience demon-
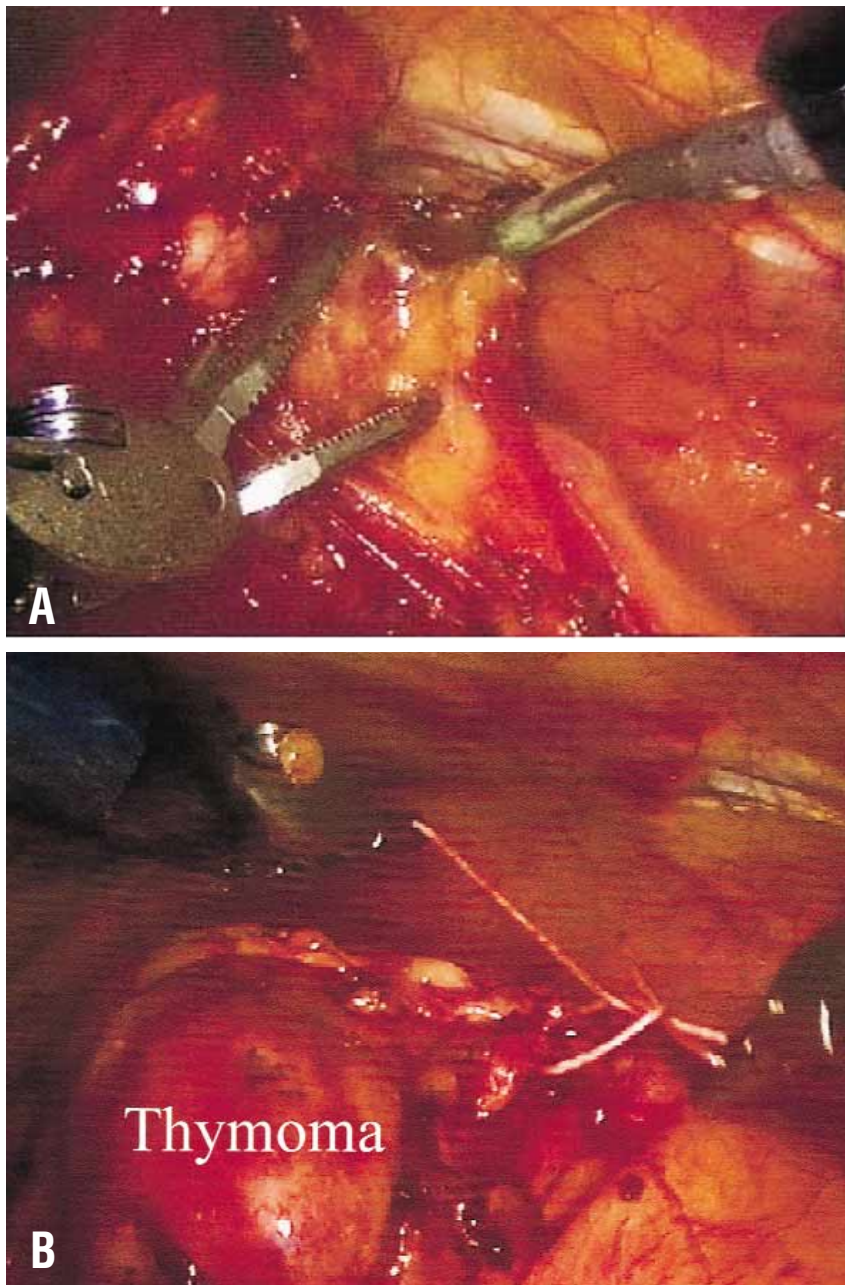

Figure 2. Intrathoracic view during the operation. A, The tumor was dissected from the caudal to cranial site by using an EndoWrist and an EndoDissector instrument. B, A drainage vein was ligated by using 3-0 Vicryl sutures and cut by using two EndoWrist devices.

strated that this approach could also be applicable to other surgical fields, including the pulmonary hilum, the cupola of the thorax, and the posterior mediastinum above the hilum. Second, both the suturing and ligation techniques used by the manipulators of this robotic system can be safely and easily performed in the anterior mediastinum. From the above results, other intrathoracic operations are therefore considered appropriate with use of this robotic system. Anterior and posterior mediastinal tumors, such as noninvasive thymomas or neurogenic tumors, may thus be a good candidates for this system because most of them show a benign nature, even when a complete resection is achieved., ${ }^{4,5}$ Ruptured pulmonary bulla may also be worthy of consideration for repair with the suturing techniques of this robotic surgical system. A conventional video-assisted thoracoscopic bullectomy that is mainly performed with a mechanical suture device is not always satisfactorily performed when the bulla is large or located on the mediastinal 
side. However, a major pulmonary resection would not be performed with this robotic system because the sense of touch of the da Vinci instrument, which surgeons feel by only 3 grades from the manipulator, is too rough to expose pulmonary vessels and requires much improvement.

In conclusion, we believe that this system can enable thoracic surgeons to perform better procedures than with conventional thoracoscopic operations because of its enhanced visualization and precision for several diseases and because robotic engineering of the next generation would be expected to be applicable to most fields of thoracic surgery. However, the safety of robotic systems, which remains the most critical factor, depends greatly on the experience of individual surgeons, as well as on the reliability of the system itself.

\section{References}

1. Loumet D, Carpentier A, d'Attellis N, et al. Endoscopic coronary artery bypass grafting with the aid of robotic assisted instruments. $J$ Thorac Cardiovasc Surg. 1999;118:4-10.

2. Reichenspurner H, Damiano RJ, Mack M, et al. Use of the voice-controlled and computer-assisted surgical system Zeus for endoscopic coronary artery bypass grafting. J Thorac Cardiovasc Surg. 1999;118:11-6.

3. Hashizume M, Shimada M, Tomikawa M, et al. Initial experiences of endoscopic procedures assisted by a computer enhanced surgical system, da Vinci. Proceedings of International Micromachine Symposium. 2000. p. 49-52.

4. Yim APC. Video-assisted thoracoscopic management of anterior mediastinal masses. Surg Endosc. 1996;112:1352-60.

5. Roviaro G, Rebuffat C, Varoli F, et al. Video thoracoscopic excision of mediastinal masses: indicators and technique. Ann Thorac Surg. 1994;58:1679-84

\section{Online-www.aats.org}

Now you can get The Journal of Thoracic and Cardiovascular Surgery online. The Journal online brings you faster delivery time, easy searching of current and back issues, links to PubMed, AATS, WTSA, and other important sites, and more. Visit the Journal online today.

\section{Receive tables of contents by e-mail}

To receive the tables of contents by e-mail, sign up through our Web site at http://www.mosby.com/jtcvs

Choose E-mail Notification

Simply type your e-mail address in the box and click the Subscribe button.

Alternatively, you may send an e-mail message to majordomo@mosby.com.

Leave the subject line blank and type the following as the body of your message: subscribe jtcvs_toc

You will receive an e-mail to confirm that you have been added to the mailing list. Note that TOC e-mails will be sent out when a new issue is posted to the Web site. 